\title{
Industrial constructions of publics and public knowledge: A qualitative investigation of practice in the UK chemicals industry.
}

\author{
Kate Burningham, Julie Barnett, Anna Carr, Roland Clift \\ \& Walter Wehrmeyer \\ University of Surrey
}

Address for correspondence:

Dr. Kate Burningham

Centre for Environmental Strategy

University of Surrey

Guildford

Surrey GU2 7XH

UK

E-mail: k.burningham@surrey.ac.uk

Fax: 44 (0)1483 686671

Phone: 44 (0)1483-686688 


\title{
Industrial constructions of publics and public knowledge: A qualitative investigation of practice in the UK chemicals industry.
}

\begin{abstract}
While the rhetoric of public engagement is increasingly commonplace within industry, there has been little research which examines how lay knowledge is conceptualised and whether it is really used within companies. Using the chemicals sector as an example, this paper explores how companies conceive of publics and "public knowledge", and how this relates to modes of engagement/communication with them. Drawing on qualitative empirical research in four companies, we demonstrate that the public for industry are primarily conceived as "consumers" and "neighbours", having concerns which should be allayed rather than as groups with knowledge meriting engagement. We conclude by highlighting the dissonance between current advocacy of engagement and the discourses and practices prevalent within industry, and highlight the need for more realistic strategies for industry/public engagement.
\end{abstract}

Key words: Publics; public knowledge; public engagement; industry.

\section{Introduction}

The desirability of recognising and incorporating lay knowledges in public and private sector scientific, technical and environmental decision making is now widely acknowledged (e.g. RCEP, 1998; Copenhagen Charter, 1999; House of Lords, 2000, Owens \& Cowell, 2002) and industry is under increasing pressure to respond to public expectations. However, engagement practices and the motivation and willingness to undertake them depend on how publics and the qualities of public knowledge are constructed by the industrial bodies themselves.

This paper reports on findings from research funded under the UK Economic and Social Research Council's "Science in Society" programme. Drawing on findings from qualitative case studies of four chemical companies, it explores how company executives characterise publics and their environmental knowledge and how this relates to their company's modes of public engagement/communication. A review of background literature on how the public engagement agenda relates to manufacturing industry underlines the importance of understanding how private industry conceives of publics. It leads to the three key research questions: who are "the publics" for industry? How is public knowledge characterised? How does this inform companies' modes of engagement/communication with their "publics"?

\section{Background}

The relationship between experts and lay publics is the subject of ongoing attention from social scientists and policy makers. In recent years, this debate has been fuelled in the UK by the drive under the New Labour government to expand public participation in policy-making and the provision of public services, in the hope of ensuring higher standards and increasing the legitimacy of institutions. Against the background of declining turnouts in elections and referendums and concerns about the 
"democratic deficit" of institutions that are remote from citizens, a range of initiatives has been proposed to engage publics. The Aarhus Convention (1998) on access to environmental information encapsulates many of these issues. In the same year, the Royal Commission on Environmental Pollution (RCEP, 1998) recommended that:

Governments should use more direct methods to ensure that people's values, along with lay knowledge and understanding, are articulated and taken into account alongside technical and scientific considerations.(para.7.17, p.104)

Although the RCEP was concerned primarily with procedures for setting environmental quality standards, their recommendations had wider implications including procedures to regulate chemicals in products (RCEP, 2003), a matter of direct concern for the industrial sector which was the focus of this research. Nor was this advocacy of a new approach confined to Europe; a broadly similar approach was advocated in the US by the National Academy of Sciences (Stern and Fineberg, 1996).

A new approach to public engagement is advocated for several reasons: to reduce conflict, to enable people to have a sense of ownership of outcomes; as part of a commitment to improving democracy and enabling people to contribute to decisions affecting their lives. It is also argued that lay people have important and distinct knowledge about sustainability issues, so that a combination of lay and expert knowledge contributes to "better" environmental decisions ( Brown, 1991, 1993; Wynne, 1996; Irwin, 1995; Dickens, 1996). The motivations for public engagement in decision-making have been categorised by Fiorino (1990) as instrumental, substantive and normative. Stirling (2004) summarises these:

Under a normative view, participation is just the right thing to do. From an instrumental perspective, it is a better way to achieve particular ends. In substantive terms, it leads to better ends. (p.220)

Most recently, discussion has focused on the need to move public engagement "upstream" (Wilsdon \& Willis, 2004): enabling public debate to take place in the development of science and technology, rather than later when a technology is approaching exploitation.

Most of the debate has concerned the way in which decisions are made in the public sector, even though recent work has highlighted the extent to which science based industry plays a key role in innovations in science and technology: see for example discussions of the "triple helix" (Etzkowitz 2003) and "mode 2" knowledge production (Gibbons et al 1994). For the advocates of public engagement, there are clear normative reasons why industry should engage with "the public" as sciencebased industry is the source of most of the developments which will affect people"s lives. Given this erosion of demarcation between university science and industrial science, social science research on industrial science is crucial for developing new understandings of publics and science. As the inclusion of lay perspectives is increasingly thought critical in achieving socially robust knowledge (Gibbons 1999), the question of the extent to which this is recognised and acted upon within industry science is important. 
Companies in the private sector are accustomed to public engagement as a statutory requirement in planning processes (Owers \& Cowell, 2002). In the chemicals sector, this arises when a new production facility is to be built or an existing plant is expanded. However, public engagement over product development, as distinct from consulting customer panels in planning product launches, can be seen as new, unfamiliar and possibly threatening (Oxley Green, 2005). Even so, some companies may decide voluntarily to adopt processes commonly summarised under Corporate Social Responsibility (CSR) which involve some element of stakeholder engagement. CSR can be considered as an approach to ameliorating the environmental and social impacts for which a company could be considered responsible. O'Mahoney (2004) identifies a qualitative change in the pressures on companies to demonstrate social responsibility; "individuals and organisations who are neither shareholder nor union member are demanding a say in how business defines, executes and reports on responsibilities that are over and above those prescribed by law" (p.10). O'Mahoney suggests that this has led to a "stakeholder route to corporate responsibility" where relationships of trust and goodwill are built with groups or individuals expected to have an impact on business operations.

The rhetoric of public participation is thus becoming increasingly commonplace and there is a growing exploration of various forms of engagement through which dialogue can be effected. However, there is little evidence that practice in private sector companies has kept pace with these academic developments. As noted above, engagement practices and the motivation and willingness to undertake them are likely to depend on the view within industry of publics and their knowledge. This study was undertaken to explore the current reality of public engagement in the private sector.

Understanding how experts construct publics is critical in any attempt to understand their patterns of public engagement. Constructions of publics and models of communication with them are often inextricable (Maranta et al, 2003; Irwin \& Michael, op cit). As Stilgoe puts it:

Studies of technology have suggested that technologies necessarily embed assumptions about users (Woolgar, 1991) (and sociologists embed assumptions about readers (Latour, 1988)), constructing their particular public. So experts, when dealing with questions of public engagement, might be seen as (re-)constructing their publics as they (re-)construct science-in-public (Stilgoe, in press)

The social construction of publics by experts is emphasised by Maranta et al (2003) who describe experts as "lay person makers" and talk of the "imagined lay persons" (ILPs) they make, arguing that "experts cannot set up ILPs without having a concept of how to communicate with lay persons" (2003: p157).

The literature discusses two extreme characterisations of publics. The technocratic, PUS or deficit model regards the public as passive, ignorant and worried "because it does not understand the science" (Irwin \& Michael, 2003: 14 \& 43). Critics of this model depict publics as active citizens who posses valid and useful knowledge relevant to decision making. How particular experts actually construct particular publics may lie somewhere between these two positions and the two models may coexist within their accounts (Irwin \& Michael, 2003: 55). 
The research reported here aims to contribute to the ways in which we can understand "expert" constructions of publics. While acknowledging that assuming a public/expert dichotomy ignores the way in which the lines between these categories are often blurred (particularly when considering the role of new social movements, pressure groups and advisory committees; Irwin \& Michael, 2003), our purpose here is to consider how publics, public knowledge and interactions with those publics are conceptualised by people occupying a range of "expert" positions within private companies in the chemicals sector. The research forms part of a larger project exploring how lay environmental knowledge is conceptualised, accessed and used within the UK Chemicals industry. Rather than considering official company policies, this paper concentrates on the views expressed by company executives about publics and the value of engagement.

\section{Methodology}

As a broad industrial sector for study, chemicals were selected for several reasons. Chemicals have long been a focus of public concern : Rachel Carson's Silent Spring (1962), which was seminal in the development of environmental awareness in the late $20^{\text {th }}$ century, provoked discussion of the health and environmental impacts of chemicals, particularly pesticides. Partly as a result, the chemical industry is relatively highly regulated. Chemical companies have therefore experienced the influence of different publics primarily via regulators so that, mirroring public concerns over the industry, companies are likely to have views about publics. The sector is characterised by complex interlinked supply chains leading to a range of consumer and professional products. It includes companies ranging in size from small to multinational, with many business-to-business (B2B) transactions as well as business-to-consumer (B2C) sales of branded goods; the distinctions between these types of companies are generally clearly delineated. Even so, it has been studied less than other sectors. Within this broad sector, specialty chemicals/cleaning products were selected as the focus for this research.

Although already rather highly regulated, the chemicals sector is currently being required to re-engineer business processes as a result of external pressures, notably the EU's REACH (Registration, Evaluation and Authorisation of Chemicals) programme (EC, 2001). REACH proposes a new regulatory approach which has made the chemicals sector in the European Union particularly sensitive to public opinion. Some agents, primarily but not solely within the industry, have argued that the measures proposed under REACH are too cumbersome to be effective and will impose costs which will threaten the viability of the European chemical industry (Erler, 2006). However, part of the argument for changing the regulatory system is that current arrangements have failed to secure public confidence (RCEP, 2003:6).

The project had both qualitative and quantitative components. In the initial qualitative phase, which is the subject of this paper, in-depth case studies were carried out by interviewing professional staff in four companies. This was followed by a telephone survey of staff in 261 companies. The four companies selected for study differed on two criteria likely to be relevant in determining how publics and public knowledge are constructed: whether they are Business-to-Business (B2B) or Business-to-Consumer 
(B2C), and size. By B2C we mean companies marketing products which are retailed to consumers (whether or not these products are first sold on to other companies), while B2B companies do not trade directly with consumers but supply to other companies.

A commitment to preserving the anonymity of the companies who participated in our research prevents us from identifying or describing them. This is perhaps unfortunate, because details of the products they manufacture, the company history and ethos all help to explain how a company thinks about publics and relates to them, but is essential, in part to avoid damaging the field for future researchers. In the most general terms, the following table illustrates the selection of case studies:

\begin{tabular}{|l|ll|}
\hline Business-to-Business large B2BL & Business-to-Business small & B2BS \\
\hline Business-to-Consumer large B2CL & Business-to-Consumer small & B2CS \\
\hline
\end{tabular}

Companies in different cells of this typology might be expected to differ in how they construct publics and public knowledge and how likely they are to have mechanisms for public engagement. We wanted to consider the different proximity to publics of B2B and B2C companies as well as the differences between companies with one or a few manufacturing sites vs. multinational companies. Small companies are less likely to have formal consultative mechanisms and less likely to display internal variability between departments on the uptake and use of lay knowledge.

Thirty four semi-structured interviews were conducted in total (between 4 and 12 individuals in each company, the number varying primarily with company size) with representatives from different corporate functions. The choice of interviewees varied between companies but all were senior executives drawn from Marketing, R\&D, Public Relations, Production, Management and Health and Safety. The interviews were wide ranging, addressing questions of definitions of the public/s, characterisation of public environmental concern and knowledge, communication with publics and policies of corporate social responsibility and sustainability. Interviews were transcribed in full and analysis facilitated by the use of WinMax software. The analysis presented here focuses on how our respondents viewed the public and the characteristics they ascribed to their knowledge, before considering how this relates to their company's patterns of consultation and engagement with publics.

Much recent literature considering interactions between experts and publics has been at pains to stress that "the public" actually constitute a plurality of "publics" (Petts, 1994; Rayner, 2003) thus highlighting both the diversity of groups making up "the public" and the roles inhabited by any one member of the public. We acknowledge this heterogeneity of publics but at times refer to "the public" as a useful shorthand. We also acknowledge that our analysis involves an element of what Woolgar and Pawluch (1995) have called "ontological gerrymandering". i.e. we proceed as though the public/s and public knowledge are unproblematic topics for investigation while maintaining that these concepts are socially constructed by our interviewees. Rather, than seeking to avoid this, we acknowledge it as an inevitable aspect of constructionist analyses (see Collins and Yearley 1992) but endeavour to make clear throughout whether we are referring to respondents' use of the concepts of publics and public knowledge or to our own. 


\section{Who are the public for industry?}

Although one of our key research interests was how our interviewees constructed publics or lay people, we quickly realised that they did not use these concepts. Rather their focus was firmly upon "consumers" and/or "neighbours" (those who live close their factories). Discussion of "the public" only really arose in response to direct questioning about what the term meant to them. We first illustrate how "the public" were constructed when they were mentioned, before going on to introduce the characterisation of "consumers" and "neighbours".

\section{"The public"}

Some of our interviewees acknowledged the plurality of publics:

The public is very wide ranging...it is our customers, it is the investment, the financial community, it is the local community, it is our staff and it's our staff globally so it's a very, very large group of people. (Leonie, B2BL).

I mean when we say public of course we have the consumers, we have the competitors consumers and we have the bodies, public sector and we have private sector business, we have organisations, we have media people, we have non-governmental organisations or non-profit organisations ... all these different roles and responsibilities of individuals just define the public. (Harry, B2CL).

The idea that multiple roles and responsibilities attach to individuals was only recognised, by a few interviewees in our large B2C company (which, as will become clear, was often the exception):

You cannot regard people as one dimensional, somebody can at the same time be a manager, a mother, a sister, a wife, a consumer, a campaigner, a local councillor et cetera... and they do that all as one individual... and decisions in one area will impact or attitudes derived from one area will impact decisions in other areas. (Aiko, B2CL)

Ideas about "the public" were linked with ideas about public opinion and public pressure; "the public" were constructed as the bearers of opinions and values which might impact upon the company:

Public for me is, in the context of this business, is more about opinions... it's more about regulatory issues, it's more about consumer affairs so that's really what public means to me... and governmental organisations, this type of thing. (Sam, B2BL)

For me the word public... how shall I put it, is an accommodation of power, meaning the public can bother you ... the public is a silent, strong force, everybody's part of it, and it can break or make you. (Les,B2CS) 
These accounts draws on ideas about individuals acting within the public realm, "the man in the street" rather than the consumer within the supermarket or private individual within the home, as the following quote nicely illustrates:

If I heard the term public I'd think about, less about people going shopping than just people in the street, I mean... if you walk outside the supermarket there's loads of people milling around, some with placards saying "Save the World", and they're the public. (Simon, B2BL)

While these constructions implicitly draw on notions of people as citizens, this term was used only by a few employees within the large B2C company; the notion of people as political actors was common within this company, confirming that the public are seen as having the power to affect politicians and thus influence regulations which might impact upon the company.

Given respondents' descriptions of the heterogeneity of "the public", they might be expected to conceptualise their categories of "consumers" and "neighbours" as subsets of this diverse general public or as two of the many identities attributed to individuals. This does not, however, capture the essence of their accounts. While "consumers" were sometimes seen as part of "the public", they were also characterised by some as synonymous with "the public" and by others as distinct from it. "Neighbours" were rarely discussed as "the public". Evidently constructions of "the public" as potentially powerful citizens do not automatically inform constructions of either "consumers" or "neighbours". In addition, while interviewees talked in abstract about the diverse roles inhabited by any member of the public, the actual publics of relevance to them tended to be seen only as consumers or neighbours (although the large B2C company allowed for consumers also to be considered as citizens). These observations support Maranta et al's (2003) suggestion that "imagined lay persons" are uni-dimensional:

An ILP (imagined lay person) usually can only protest or buy products or help build a dam but cannot perform all of these functions together (op cit : 156)

But our findings suggest a more complex interpretation: respondents recognised the concept of a heterogeneous and potentially powerful public, but tended to discuss publics they actually "knew" directly as uni-dimensional.

\section{Consumers and neighbours}

Notwithstanding the broader concept expressed by some interviewees in the B2CL company, for the two B2C companies, whose products are on the shelves of supermarkets, the public were primarily constructed as consumers of these products. Both companies had developed detailed and sophisticated typologies of their consumers, drawing distinctions along such lines as particular values, preferences and economic status. The two companies conceptualised their "consumers" very differently, however. For the B2CL company, almost everyone is an actual or potential consumer of their products:

The market is pretty much everywhere, it's everybody uses such things, ... it's a completely global market, it's in every country in the world, we sell to all 
socio-economic classes of consumers so it's a huge market, it's everywhere. (Bill, B2CL)

As the public and their consumers are seen as one and the same, the company has a clear interest in understanding the variety of public concerns, interests and priorities; ideas about "the general public" as citizens with political and social interests transferred onto their construction of their consumers.

By contrast, the B2CS company identified their consumers as a very specific subset of the public with particular interests and values:

We've done some sort of demographic surveys and we know that our consumers are likely to be older they're more likely to be mothers of 28 to 35 rather than 20 to 30 for example; they're more likely to be people that are more affluent and they're more likely to be more educated. (Cheryl, B2CS)

When participants from this company talked about "the public" they often described them as lacking environmental knowledge, concern or interests, as those who possess these attributes were already separated out into the category of possible or actual consumers of their products:

I: do you think the people who buy your products are different from the general public?

Amanda: Yes I think so... I think that they are more concerned about environment, that they are better educated. (Amanda, B2CS)

We expected our B2B companies to be less focussed on consumers, as they have no direct consumer sales and so might be less concerned to understand consumer concerns and behaviours. Those interviewed in the small B2B company equated the public with consumers but described these people as "far away from us":

We are X number of stages away from the public...It's not an issue, we have no direct sale to the public, ...nothing goes out of here directly to the public and we have no market developed for that, we have no licence for that, we are not approved to that, it's the wrong area for us. (Pedro, B2BS)

However, the large B2B company revealed a different picture; this suggests that closeness to consumers should not be understood simply in terms of the number of links in the value chain but may also be influenced both by company size and visibility and by the nature of the product. While this company does not sell products directly to consumers, it operates with a keen interest in consumer perceptions and preferences:

Ostensibly we are a B2B company... we don't sell to the public direct... Having said that... we are in relatively regular contact with consumers via market research ... So in one sense we sell direct to customers as opposed to consumers and in the other sense, to do that properly we have to understand what their preferences are, what their tastes are. (Miles, B2BL) 
So far we have illustrated that both B2C companies and the large B2B company focus on the public primarily as consumers, but to varying degrees also operate with a model of the public as active citizens. For the small B2B company, consumers were conceptualised as too far away to focus upon; however, staff in this company recognise a much closer "public" of concern to them - people who live close to their factory:

The public I see as our neighbours so that's going to be any local residents, it's going to be any local companies that are adjacent to us, anyone in the vicinity is the public to me by the nature of what we, what we do and the risk of what we do, there's always that possibility that at the end of the month we've an unforeseen incident, we could have an effect on the neighbours....so to me it's the public at large in the area, yeah that's the definition of that. (Saul, B2BS)

Local publics were also acknowledged as important by some interviewees in the other companies:

Yeah, actually there is another important angle ...I mean we have a facility and a factory here so the public for me are the people who live and work around the factory. (Mitchell, B2BL)

\section{Characterising public environmental knowledge}

So far we have explored the various ways in which interviewees characterised the public. We turn now to a consideration of their characterisations of public environmental knowledge. We look first at how the concerns of "the public" were characterised, before turning to the particular concerns of "consumers" and "neighbours".

\section{“The Public's" environmental concerns}

Our respondents characterised "the public" as having a range of environmental concerns but little "knowledge". Public concern was understood as informed by selfinterest and the immediacy of problems:

I think it's very limited and I think it starts with their own health, their own environment ... because the environment I think overall is something people cannot really grab. (Marko, B2CS)

I think that people generally speaking are, and I don't mean this in a nasty way but are pretty self-motivated, a little bit selfish and are, are only girded into action when they can see you know the direct impact on them or their loved ones. (Mitchell, B2BL)

This provides a clear example of a contingent discourse being used to account for "the public's" environmental knowledge (Gilbert \& Mulkay, 1984; Burchell, in press). While respondents described their own knowledge as based in "hard" science, they characterised "the public's" environmental concerns as essentially self- interested, implicitly devaluing them as partial and selfish. 
Along with self-interest, media coverage and NGO activity were identified as key in shaping public attitudes and concerns. Interviewees argued that the media was the main source of information for "the public" and had a strong influence upon their concerns and knowledge:

These days ninety-nine percent of what people know comes through television so it's based on whatever programming there is on the television. (Simon, B2BL)

I suspect the public knows what they see in the popular press and they probably some of them, they know what's topical at the moment. (Bill, B2CL)

Respondents were generally negative about this influence, depicting media content as partial ("completely biased"), superficial ("based on sound-bites"; "almost no detail") and preferring bad news to good news ${ }^{1}$. Particular concern was expressed regarding media "scare" stories about chemicals and the chemical industry which, interviewees argued, provided misinformation and created unfounded anxiety:

I think something prevalent now called chemo-phobia... which means an unwarranted fear about the role of any particular chemicals. You've only got to open a newspaper and people are talking about weapons of mass destruction and linking it with chemicals. (Jack, B2CL)

This concern about media influence on public environmental knowledge reveals, a linear or transmission model of knowledge transfer from the media to "the public", who are depicted as passive recipients of partial, biased and sensationalist information.. There is little recognition that members of the public may have prior knowledge of their own, be able to draw on multiple sources of information or actively evaluate information (Burgess \& Harrison, 1993; Hansen, 1991; Petts, Horlick-Jones \& Murdock, 2001). While the media were criticised for providing misleading accounts, several interviewees identified the real "villains" as NGOs who were seen to exert a powerful influence on media messages and thus on public opinion:

I think the media's only relaying the message isn't it, they're amplifying it a bit but it's really the pressure groups, it's NGOs that are pushing. (Andrew ,B2CL)

As you dig a bit deeper I think the concerns are, to a great extent, raised by NGOs and they feed the press and the public. (Terry, B2BL)

\section{Consumers' environmental concerns}

In addition to discussing the general environmental concerns expressed by "the public", interviewees in both B2C companies and some in the large B2B company talked about a range of current or potential public concerns over the environmental impact of their products. However, interviewees attempted to downplay the extent and

\footnotetext{
${ }^{1}$ See Burchell (in press) for an almost identical account of public environmental concern by scientists working in crop genetics.
} 
significance of these concerns in two ways. The first type of response was that consumers simply did not prioritise environmental issues, or pay attention to environmental performance in product choice, but were more interested in whether the product worked and was reasonably priced:

Because I think, I think that the very front of people's minds, if you're making a choice about, do I buy the green version or do I buy the non-green version of something, the first thing that people think about is the price. (Simon, B2BL)

And they want performance number one and they want cost number two and environment is pretty well down the list. (Andrew, B2CL)

The second, complementary argument was that it is the company's responsibility to ensure that products meet health and safety criteria and are responsibly produced; thus consumers should not, or need not, have concerns over the environmental impacts of their purchases:

In a very blunt way the product has to do its job and you at (Company) have to take care of the environmental issues; it's kind of a mandate to do that for the consumer and I think personally this is the right way to handle it.

(Paulo,B2CS)

So that's where I think we don't get the lay effect, and I think when you look technically at what's going on you know the industry regulates itself and manages itself and responds well to the consumer groups and the lobbyist groups. (Sam B2BL)

Ideas about the proper roles of ordinary consumers and experts within corporations come into play here. Consumers are constructed as not having the requisite knowledge (or the interest) to weigh up the potential environmental impacts of products; the public can and should trust the experts to do this. This is clearly at odds with notions of the consumer-citizen who might have both an interest in and a right to be engaged in discussions about the environmental performance of products.

These reservations aside, interviewees listed a range of product environmental issues which are concerns for some consumers. Key issues were: the biodegradability of the product and its effect on water quality; packaging and waste; animal testing; chemicals in general; and health and safety issues. While interviewees depicted consumers as having environmental concerns about products, they did not view them as having knowledge about the product. At best, consumers were depicted as having relatively superficial "soft" knowledge about the product, usually lacking "hard" scientific understanding:

If you asked the average person in the street about the science, the chemistry behind our products, you know, they wouldn't know...I don't think that people really know or want to know. (Len, B2CL)

\section{Neighbours' environmental concerns}


While interviewees in the small B2B company acknowledged that consumers may have concerns about final products containing their chemical intermediates, they did not see these concerns ever passing up the supply chain to them. Issues that concerned local residents were seen as far more relevant to them, particularly concerns over. risks and impacts associated with living near the factory:

To us, yes I mean our biggest impact, our direct impact is do we produce any smells? Is there a noise...? Is there traffic from the lorries that come into our plant? That's our interaction with the public is that...nothing to do with the primary manufacturing process here whether our products taste nice or look nice... ours is entirely about, I'll say nuisance value that is caused by any factory. (Pedro, B2BS)

Neighbours' concerns about risk were often described in terms of "perceptions", in contrast with the "reality" known to the industry scientists. Local people were thought to depend on what they could see, hear or smell for information about potential dangers, with the suggestion that these senses may not be reliable indicators of environmental risk:

I mean we used to make a product here that was quite smelly and that was much more noticeable than ... a bromine spill. ..A chemical spill or whatever ...may go unnoticed to the general public but it's far easier to notice a fishy smell that's around the site .... but it's not really bad... it was not polluting the atmosphere you know, it's perfectly healthy, .... and safe ...more people notice it because they can smell it. (Amy, B2BS)

Concerns about specific local hazards were sometimes seen as underpinned and amplified by more fundamental suspicions about the chemical industry. This anxiety too was characterised as essentially a misperception:

Perception is not necessarily reality. If you take the views of our local residents ... their concerns are a perception that industry is the dark satanic mill ...there is an almost a cloak and dagger perception of industry that they have, something secret going on, something nefarious that looms at night when no one can see and this sort of stuff. I think there's a level of, well there is, I know, there's a massive level of ignorance about what industry does. (Pedro, B2BS)

\section{Shades of the deficit model}

The previous section outlined interviewees' ideas about "the public's" general environmental concerns as well as consumers' and neighbours' more specific concerns related to their products and factory operations. Their accounts give some indication of their constructions of the character of public knowledge; for instance, we have illustrated ways in which a deficit model is implicitly adopted, with the public depicted as passive receivers of partial, biased and sensationalist information from the media. Publics are seen to lack both relevant knowledge of their own and the ability to draw on valid sources of information; the information they (passively) receive is not viewed as a sound basis for knowledge. In addition, public environmental 
concerns were thought to be driven primarily by special interests, an explanation which implicitly devalues them as selfish, narrow or superficial. Neighbours' concerns about factory operations were described as based on their senses, and by virtue of that deemed inaccurate. Thus a picture emerges of public knowledge as deficient in both extent and quality. We now consider in more detail two variations on the deficit model employed by interviewees and how these models inform companies' perspectives on public engagement.

\section{Public understanding of the chemical industry}

When respondents in the small B2B company talked about public knowledge of the chemical industry, "the public" were characterised as ignorant:

Yeah and that's what I'm saying, I think generally the public at large are very ignorant and they just see the chemical industry as this you know, this nasty little...industry where you have a plant stuck in the middle of nowhere, producing all this fume and smoke and dust and chemicals and very underhand. (Saul, B2BS)

This characterisation was accompanied by the familiar response that the deficit should be rectified by providing education and information:

We do... open the door and let people in and the Open Day we did last year that was open to anybody to come to that and see and they get a tour to give them more of an insight...So we're not the scary, scary place down the road... and we're not all mad professors in labs and that's what they expect you know, they expect a mad professor to be working in a lab or something. (Marilyn, B2BS)

It's how we try and dispel the satanic mill argument, it's very much here's what we do, come and see, understand, you're actually talking about education...It's about making sure people understand what you do and they can make informed judgements. (Pedro, B2BS)

What is apparent here is concern to address deficits not only of knowledge of the process of science (rather than the content) but also of public trust in the industry by "opening their doors" and inviting people in. Reframing the problem "as one of lack of trust rather than one of irrational public conceptions of risk" (Owens 2000:1142) might be seen as a step in the right direction: an acknowledgment of the fundamental role that lack of trust in the institutions responsible for managing risks plays in public assessments of risk (Wynne 1992). What seems to be happening here, however, is that notions of an ignorant public remain and are extended rather than replaced; lack of trust in the industry is characterised as a further dimension of ignorance and irrationality, rather than a rational appraisal based on prior experience and knowledge.

\section{Public understanding of the science behind the product}

While interviewees' accounts of public understanding of the chemical industry clearly conform to the deficit model, their discussions of public understanding of the science behind products and their potential environmental impacts (what's in it; how it's made; impacts in production, use and waste) reveal a more complex picture. Certainly 
one dimension of the deficit model is evident: the public are seen to lack knowledge and not to know the facts:

Sometimes you have people who presume they have all the knowledge but you ask them one or two questions and it's finished, especially when they talk about biodegradability. If you ask one or two questions they can't answer any more so I think $99 \%$ are not aware. (Charles, B2CS)

However, this ignorance was not seen as something to be rectified; interviewees did not advocate providing information and education to improve public scientific knowledge. Instead, consumers' deficits of knowledge about the science behind products were explained or defended in a number of ways. One argument was that the science is too complex for most lay people to grasp:

It's a terribly complex so much is chemistry - chemistry it's physical things, it's physical chemical issues that you have to deal with ... I don't say it is extremely difficult and laymen cannot understand it...but it's very complex. (Paulo, B2CS)

Public "ignorance" about industry science was also defended by arguing (as outlined above) that regulation ensures that products meet stringent health and safety criteria and thus consumers need not have concerns or knowledge about their purchases. A third way pf constructing knowledge deficits as understandable was to question why anyone would want to acquire such knowledge. Respondents often questioned whether their products were really of public interest:

They buy them and use them every day but I don't think they give them a lot of thought. Usually we find if we talk to them about what's in a product, how it works, they've got very little knowledge and understanding about it ... And to be honest I don't think they give them a lot of thought actually. (Andrew, B2CL)

Thus interviewees defended the perceived deficits of knowledge by arguing that people are not interested in acquiring knowledge and have no need to do so. This range of justifications of ignorance raises interesting questions about the impact of this version of deficit model. The "classic" deficit model emphasising education, at least leaves open some communication with the public. In contrast, the way of thinking illustrated here - "they don't know, but why should they?"- implicitly legitimates lack of communication and discourages public engagement with industry science. Alternatively, and more positively, these accounts can be likened to critiques of the deficit model which point out that ignorance may be an active choice; people will only seek knowledge if it is in their interest to do so (Michael, 1996).

Although deficit models of public knowledge are clearly alive and well in the chemical industry, not all respondents utilised them. Once again, within our large B2C company some respondents presented an alternative view, acknowledging that lay people may have different but equally valid perspectives:

Your scientist tries to objectify and quantify and put numbers on it so it's one death in a thousand. The lay person interprets the information differently: 
'well I don't care how many it is, one is too many' and that's a more emotional response; it's still valid and it's still an important consideration in what we do. (Bill, B2CL)

Now I firmly believe that risk is a cultural construct, that it's not a fixed entity, it's a very varied entity dependent upon the beholder, dependent upon their beliefs and their experiences because what is risky to one person won't be risky to somebody else and therefore you've got to say that the public's views of risk will change... they will change through time, organisations views of risk will change as well. (Mick, B2CL)

These accounts indicate acceptance of the validity of different forms of knowledge and of shifts in knowledge over time. This acknowledgment of the cultural context of knowledge and the validity of lay knowledge signals a rejection of deficit models, accepting that valid information for industry decision-making is not only scientific but also potentially emotional, cultural, and based in people's values and priorities. There is a sense of willingness to engage with questions about the "values, vision and vested interests that motivate scientific endeavour" (Wilsdon \& Willis, 2004:18)

\section{Constructing and engaging with publics}

In this section we explore how our four companies communicate and engage with their publics and highlight how this relates to the ways they construct those publics.

\section{Communicating with consumers}

Our B2C companies revealed a range of ways of communicating with consumers. Information was provided through channels ranging from adverts and information on packets to company reports and pamphlets. Both B2C companies emphasised their carelines (telephone numbers provided on product packaging which consumers can call for information) and websites; these channels go beyond dissemination of information to enable consumers to contact the company Both these companies depicted contact through these channels as coming primarily from their "consumers", usually requests for advice or complaints about products.. Publicly initiated communication about issues going beyond the product (e.g. company conduct, environmental record, animal testing) was depicted as comparatively rare and only coming from people who had a particular use for such information. One such group was students and another was campaigners or activists:

I think it also depends upon what the motivation for the call is; if they're really cross about something they want to talk to somebody; if they're mildly interested in something they may just want to read what's on the website; if they're a campaigner and they're trying to engage other people they might want to use our response as a way of doing that. (Jack, B2CL)

The modes of communication used by the B2C companies clearly rely on a conceptualisation of the public as consumers who are only interested in product related issues. When people contact the company about broader issues, they are no longer identified as consumers but, to explain their unusual request, are characterised as "students" or "activists". The attribution of these identities arguably de-legitimises such requests for broader information or discussion; those seeking it are characterised 
as only wanting it for a specific purpose - to secure a good grade or to arm them in a particular campaign.

Most "consumers" contacting companies were thought not to want either to begin a dialogue with the company or to influence its staff or policies; rather, they were seen as wanting to make a point or gain advice, information or recompense:

Let's face it, a lot of the communication does not invite dialogue, they want to make their point and that's what they're doing. (Aiko, B2CL)

Customers who contact you, it's usually ceremonious. (Cheryl, B2CS)

If public contact is understood as "ceremonious", people simply "wanting to make their point", then public engagement is seen primarily in terms of making sure that people feel that they are being taken seriously and their concerns are being allayed, rather than as a potential source of new ideas or useful knowledge for the company. Our respondents confirmed this, explaining for instance that "for most people, a company reacting, acknowledging the concern is enough". Of course B2C companies are particularly keen to collect information about consumer behaviours, preferences and concerns but this is market research, directed at understanding the public as consumers and focusing on their behaviour in the market place. In our large B2C company, however, there was also evidence of interest in understanding publics which went beyond a focus on the market. This research, carried out with academics rather than market research agencies, indicates a desire to develop deeper and more sophisticated understandings of peoples' values and concerns:

Ever since I've been involved in the company there has been a real commitment to foster discussion of difficult subjects in the environmental area by lay people and to put that in academic environments that are willing to consider in an open way, what the response is actually going to be and I would see that absolutely as a manifestation of our interest in the consumer as a citizen. (Aiko, B2CL)

\section{Communicating with neighbours}

When the public were regarded as "neighbours," their interests were always constructed as local concerns, about issues such as factory risks and other "nuisances". As already noted, these concerns were often described as "perceptions" which should be rectified through education and by presenting of the industry as friendly and open. Once again, the appropriate response to this concerned public was framed largely in terms of offering reassurance.

Research into local concerns was rarely mentioned, but companies do try to develop an understanding of their neighbours' views and concerns, not from formally constituted research but through direct interaction between company representatives and local people. This interaction typically involves local meetings specifically to hear about any local concerns, but which may encompass discussion of diverse issues: 
So you can imagine you're there talking about the weather ... if they want to talk about that, that's their right. I'm not there to dictate that this is a useless meeting, I don't want to talk about the weather, but the fact that we are talking, ..., I'm trying to suggest we don't dictate to say we must talk about... any of our meetings with the local community are chaired by the community, we will host them here, throw on some sandwiches, some cups of tea, give them a room to talk to us in. It's very rarely anything that's contentious though, we have a very good relationship in that sense. (Pedro, B2BS)

Although such meetings could be viewed as another attempt to offer reassurance along with sandwiches and cups of tea, perhaps this is too cynical a reading. Such fora may provide space for building trust between the company and their public and an opportunity to explore issues which go beyond the concerns which "neighbours" are assumed to have.

The companies also detailed a range of parallel "outreach" activities including open days, social events, working alongside local charities, working with schools, involvement in local development fora and local environmental initiatives. These activities were seldom depicted as driven by an interest in understanding neighbours' concerns, but were more likely to be seen as an essential constituent of being a responsible company, working with and responding to the "local community":

We had a commitment to managing our business in ethical...., it sounds almost pompous but it's not meant that way, it's just trying to have a wider consideration in line with our policies that we put out. .... One of those issues is about our husbandry, for want of a better word, of the local community. Do we give anything back? do we listen to their concerns? and we try as ..a relatively small company, we try and ensure that we do listen to any issues they've got. And we act on them, we can't promise them the world but you can say "yes, we will try to listen to your concern and do something about them if it's in our power". And that's not a throwaway sentiment either, it's essentially what we do try and do. (Pedro, B2BS)

All the interaction with "neighbours" or the "local community" took place within the locality and revolved around local concerns. This local public was not also seen as having the identities and interests of "consumers", "activists" or the "general public". Irwin and Michael (2003) argue that "lay publics can no longer be thought of solely in terms of embedded local communities: as if they were separable from larger social forces and changing cultural patterns" (p85) yet this is just how our B2B companies think about their "neighbours".

\section{Communicating with "the public"?}

Thus the public are largely viewed as either "consumers" or "neighbours". Accordingly every contact between companies and publics was framed as seeking information or expressing concerns about either the product or the factory, requiring reassurance more than engagement. Consumers and neighbours were not regarded as the source of "facts", or broader values, "wisdom" or insights which might inform company thinking and practice (see Irwin \& Michael 2003: 8). This kind of broader lay environmental knowledge appears to be recognised and taken seriously by 
companies only when it comes from a bigger more powerful public such as an NGO. A clear distinction is made between the concerns of "consumers" and "neighbours" which need to be responded to but rarely necessitate any change within the company, and the issues raised by NGOs and other powerful stakeholders which may have a more profound impact:

What, what tends to happen, what tends to happen is that the issues that make a big impact are the issues that are, that are being raised if you like not just (by) the public but through people who have an input. (Trevor, B2CL)

I think the groundswell of opinion that has made the changes that are made through the industry associations or through our customers needing to address certain issues or an EU directive which was a response to consumer concerns so en bloc yes, consumer concerns have changed processes, but I cannot think of an individual instance that has changed a process directly here at this company. (Leonie B2BL)

I don't think that in fact that lay environmental concerns would be enough, I think it would be environmental concerns by people who are a bit more informed and a bit more vocal who can actually do something, who can say well actually we think this isn't right or wrong and what are you going to do about it but it may make a difference to something that (company) would do. (Peter B2BL)

\section{Discussion and conclusions}

This study contributes to understanding in four related areas of current interest: the relationship between models of publics and modes of interaction with them; the variety of deficit models and their implications; the dissonance between the literature on public engagement and practice within industry; and the issue of how industry might most realistically be encouraged to engage with publics.

With respect to the first of these, we found that rather than focusing on "the public" (who were acknowledged to be a potentially powerful force) company executives tended to talk about "consumers" and "neighbours". Some interviewees had multidimensional views of publics, talking specifically, and differently, about neighbours, consumers and "the general public", while others referred exclusively to one of these categories as comprising "the public". This reinforces the observation that the construction of the public is inextricably bound up with both characterisations of their knowledge and modes of engagement with them. When the public in view are "consumers", industry is keen to understand their consumption practices and priorities and their views on products; however, these contributions do not tend to be described as "knowledge". When "neighbours" are focused upon, responsible industries try to ensure that their operations do not have negative impacts upon them and if local people raise concerns they try to assuage them. The public are regarded not primarily as holders of knowledge - and certainly not environmental knowledge - but rather as people who may present concerns and complaints. If publics are constructed as concerned then the appropriate model of interaction is one of reassurance rather than engagement (Stilgoe, in press). Only NGOs or other powerful stakeholders are viewed as likely to raise social or environmental challenges to companies. The contribution of 
these stakeholders comes closest to being viewed as "lay environmental knowledge" which deserves to be taken seriously. Yet industry relations with NGOs are at best ambivalent. NGOs are described as "troublemakers" pushing environmental scare stories into the media to fuel public concern, yet their influence means that industry cannot afford to ignore them.

One of the issues we have pondered as we conducted this research was what kind of lay environmental knowledge might be of value to chemical companies? Much of the literature which seeks to establish the value of lay environmental knowledge focuses on local identities and place-based experience. For example, Wynne's seminal and celebrated study of Cumbrian sheep farmers (1989a) emphasised the value of their knowledge of local geography as well as their distinct knowledge and skills as sheep farmers; obviously experts would be ill-advised to neglect this source of knowledge in making decisions about local sheep farming practices. But the relationship between experts and publics in our study is different: our "experts" are managers within chemical companies, and the lay people are consumers of their products and neighbours of their factories. However, these people arguably do have knowledge of potential value to the experts. As users, members of the public may have experience of products which differs from information gathered in laboratory conditions and derives from longer term experience than is available when a product is launched (see Wynne 1989b). As neighbours of factories, members of the public understand local impacts in terms of what they see, smell or hear from the factory and how local people and the local environment may be affected by the company's operations, going beyond the anticipatory concerns which are raised in planning enquiries. (Brown: 1993; Irwin: 1995). It was very rare, however, for respondents to conceptualise public contributions as comprising these kinds of "facts" (Irwin \& Michael 2003:8). Neighbours" concerns about factory nuisance were often conceptualised as "misperceptions" rather than valid knowledge, and consumer comments about failings or side-effects of products were often put down to mis-use. While companies (especially large organisations and those who sell products to consumers) generally have procedures to pre-empt, elicit and respond to contacts from the public about their products and their factories, these contacts are still treated as concerns to be assuaged rather than useful knowledge.

The other reason why the public might be seen as making a useful contribution to scientific and environmental decision making within industry is because they hold important knowledge about social values and managing uncertainties which is relevant to the management, use and prioritisation of scientific and technical developments. We found very little recognition of this. Valid knowledge for the kind of decisions made within industry was conceptualised as primarily scientific and economic; i.e. "specialised" or "expert".

Our exploration of the ways in which staff in the chemical industry characterised public knowledge prompts new reflections on the problems of deficit models. Our interviewees generally interpreted public concerns about factory safety as issues of trust rather than simply scientific ignorance. However, rather than responding by trying to build trust through engagement or dialogue, lack of trust itself was constructed as irrational with the appropriate response identified as education to correct misperceptions. Public knowledge about the science behind products was also characterised as irrational or ignorant, but now without any corresponding drive for 
public education. While this is arguably informed by an understanding that people will only seek information when it is in their interest to do so, it is worrying that there is little enthusiasm within companies for engaging publics in discussions about science. As Owens (2000:1144) notes, rejection of the deficit model does not mean that attempts to further scientific understanding should be abandoned.

Our research highlights a dissonance between the literature on public engagement and practice within this industry. Overall we found little sense of broader or "upstream" public engagement either happening or regarded as necessary or desirable.

Communication with publics focuses on downstream risks, impacts and preferences (associated with products and factories) and there is little sense of the desirability of engaging with broader questions about the "values, assumptions, visions and vested interests" (Wilsdon \& Willis, op cit) that underpin company activities. Although the literature suggests that instrumental motivations for engagement are less valid than substantive or normative motivations, which are devalued, as "PR", instrumental motivations are bound to dominate. While companies may respond to normative arguments and acknowledge the substantive benefits of public engagement, it is unlikely to take place unless business benefits are clear.

Our large B2C company stood out from the others we researched as they had experience of carrying out systematic processes of public engagement. Of course, within our typology, this was the most likely company to exhibit commitment to public engagement; as a profitable and well known multinational, they have the resources and motivation to invest in ensuring that their relations with the public (all of whom they regard as potentially their consumers) are as good as they can be. The attitudes of interviewees in this company differed markedly from most others - we found people talking about consumer-citizens, rejecting deficit models of public knowledge and looking for ways to engage the public even in 'difficult' issues". Wilsdon and Willis (2004:49) suggest that apart from some "honourable exceptions"

the sector where public engagement is most urgently required is barely engaged with this agenda.

Our B2C company is clearly one of these "honourable exceptions".

This leads to the fourth question: whether it is realistic to expect many companies to commit to public engagement as advocated and described in the academic literature. This typically involves processes such as citizen juries, consensus conferences or stakeholder dialogue to engage diverse and plural forms of public knowledge in discussions about "upstream" and broad ranging issues. As our respondents pointed out (and has long been recognised) these processes are expensive and time consuming and may raise issues which the company is not able to deal with. Furthermore, many of our respondents questioned whether there is a real public desire for engagement on broader issues; the fact that little public engagement was occurring was viewed as evidence of lack of demand. While the literature on public engagement often assumes that there is a public eager to be engaged, an increasing range of studies document the practical difficulties of encouraging dialogue (Owens \& Cowell, 2002) and question the value for publics themselves of being involved (Owens 2000). As Gregory (2005) points out, both industry and the public must see some value in engagement for it to happen - it seems that often this is simply not the case. 
This is not to say, however, that valuable communication between specific companies and particular publics is not happening. Our small business-to-business company is an example of the kind of company least likely to see any value in formal processes of public engagement: their resources for public communication are extremely limited and they are practically invisible to the public, except those who live close by. Within the chemical sector such companies are in the majority. While the general model of public engagement advocated in much of the literature seems irrelevant for such companies, they often have well developed ways of interacting with their neighbours. These forms of local interaction are never labelled as "public engagement" yet may offer as much potential for mutual dialogue and building shared understandings as any formal process. Indeed, as Wynne has suggested (1989a), it is often through building informal relationships that mutual trust, understanding and respect can be developed.

There is a need to think more realistically about industry's motivations and opportunities for engagement with publics; academic discourse on public engagement is clearly out of step with the discourse inside industry. Rather than criticising industry for failing to engage citizens upstream, it would be more productive to start with industry's own conceptions of publics and points of contact with them and consider whether, and how, these might be developed to engage on issues broader than those which the industry currently thinks should concern "consumers" or "neighbours". Our research reveals the nature of this challenge: companies will have to develop beyond viewing their publics only as "consumers" or "neighbours" with the associated limited and local engagement. If industry is to broaden its public engagement, it will be necessary to start from the instrumental perspective of exploring what benefits could result, to promote views closer to those found in some of the staff of our large consumer-oriented company.

Research within the commercial sector is an important component of work on what Irwin and Michael (2003:158) have called (half seriously) PUSSSSUP (the public "understanding" of science and society and science and society's "understanding" of the public), but to date there have been comparatively few studies of industry practice. This may reflect the difficulties researchers face gaining access to private companies as compared to university, government or public sector scientists, and the confidentiality constraints which companies may impose. Despite these challenges, there is great scope for fruitful social research in association with science-based business. One of the keys is to construct research agendas which engage both academic and business interests (RSA, 2005). Debates about the opportunities and challenges of public engagement should be one such topic.

\section{Acknowledgements}

We are grateful to the ESRC Science in Society Programme for providing an award which financed the research reported in this paper, and to two anonymous referees and the editor for helpful comments. 


\section{References}

Aarhus Convention (1998) Convention on Access to Information, Public Participation in Decision-making and Access to Justice in Environmental Matters, United Nations ECE/CEP/43, agreed in Aarhus, Denmark, 23-25 June 1998

Brown, P. (1991) "The Popular Epidemiology Approach to Toxic Waste Contamination" p133-155 in Couch, S.R. \& Kroll-Smith, J. (eds) Communities at Risk: Collective Responses to Technological Hazards New York: Peter Lang.

Brown, P. (1993) "When the Public Knows Better: Popular Epidemiology", Environment Vol. 35, No. 8, pp17-41.

Burchell K. (In Press) Empiricist selves and contingent "others": the performative function of the discourse of scientists working in conditions of controversy, Public Understanding of Science

Burgess, J. \& Harrison, C. (1993) "The circulation of claims in the cultural politics of environmental change" in Hansen, A. (ed) The Mass Media and Environmental Issues, Leicester University Press.

Carson, R. (1962) Silent Spring Boston: Houghton Mifflin.

Collins, H. \& Yearley, S. (1992) "Epistemological Chicken" p301-326 in Pickering, A. (ed) Science as Practice and Culture, Chicago: University of Chicago Press.

The Copenhagen Charter: A Management Guide to Stakeholder Reporting (1999) Ernst \& Young, KPMG, PriceWaterhouseCoopers, House of Mandag Morgen.

Darier, E., Shackley, S., \& Wynne, B. (1999). Towards a "folk integrated assessment" of climate change? International Journal of Environment and Pollution, 11, 351-372.

Dickens, P. (1996) Reconstructing Nature: Alienation, Emancipation and the Division of Labour London:Routledge

EC (2001) Commission White Paper of 27 February 2001 on the strategy for a future chemicals policy, COM (2001) 88.

Entwistle, V. A., Renfrew, M. J., Yearley, S., Forrester, J., \& Lamont, T. (1998). Lay perspectives: advantages for health research. BMJ, 316, 463-466.

Erler (2006) Framework for Chemical Risk Management under REACH PhD dissertation, University of Surrey.

Etzkowitz, H. (2003) "Innovation in innovation: the Triple Helix of universityindustry-government relations” Social Science Information 42 (3) pp293-337

Fiorino, D. (1989) "Environmental Risk and Democratic Process: a critical review" Columbia Journal of Environmental Law 14501 
Gibbons, M., Limoges, C., Nowotny, H., Schwartzman, S., Scott, P., \& Trow, M. (1994) The new production of knowledge: The dynamics of science and research in contemporary societies London:Sage

Gilbert, G.N \& Mulkay, M. (1984) Opening Pandora”s Box: A Sociological Analysis of Scientists” Discourse, Cambridge: Cambridge University Press.

Gregory, J. (2005) "What are the benefits of Public Engagement?"

http://www.techforum.org.uk/guidance/pdf/what_are_the_benefits_of_public_engage ment_jg.pdf

Hansen, A. (1991) " The media and the social construction of the environment", Media, Culture and Society Vol. 13 (1991) 443-458

House of Lords (2000) Select Committee on Science and Technology, Science and Society; London:House of Lords.

IEGMP (2000) Mobile phones and Health, Didcot, UK: NRPB.

Irwin A and Michael M (2003) Science, Social Theory and Public Knowledge, OUP: Maidenhead.

Irwin, A. (1995) Citizen Science: A Study of People, Expertise and Sustainable Development, London:Routledge.

Jackson, T. (2005) "Living better by consuming less? Is there a "double-dividend" in sustainable consumption?" J. Ind. Ecol. Vol 9, No.1, pp.19-36.

Maranta, A., Guggenheim, M. Gisla, P. \& Pohl, C. (2003) "The reality of experts and the imagined lay person" Acta Sociologica Vol 46 (2) pp150-165.

Michael, M. (1996). "Ignoring science: discourses of ignorance in the public understanding of science". In A.Irwin \& B. Wynne (Eds.), Misunderstanding Science? The Public Reconstruction of Science and Technology (pp. 105-125), Cambridge: Cambridge University Press.

O"Mahony, Joan. "The Stakeholder Route to Corporate Social Responsibility." Risk and Regulation 7, Summer (2004), p. 10.

Owens, S. (2000). "Engaging the public": information and deliberation in environmental policy, Environment and Planning A 32:1141-1148.

Owens, S \& Cowell,R (2002) Land and Limits: Interpreting Sustainability in the Planning Process, London: Routledge.

Oxley-Green, A. (2005) Stakeholder Participation in Company Approaches to Sustainable Development EngD Portfolio Vol II, University of Surrey. 
Petts, J. (1994) Effective waste management: Understanding and dealing with public concerns, Waste Management and Research, 12, 207-222

Petts J, Horlick Jones T and Murdock G (2001) Social Amplification of Risk: The Media and the Public. Health and Safety Executive Contract Research Report 329/2001, Sudbury: HSE Books

Rayner, S. (2003) "Democracy in the age of assessment: reflections on the roels of expertise and democracy in public-sector decision making" Science and Public Policy, vol 30, no.3, pp163-170

RCEP (1998) : Setting Environmental Standards, 21st Report of the Royal Commission on Environmental Pollution (CM 4053) London, the Stationery Office.

RCEP (2003), Chemicals in Products: Safeguarding the Environment and Human Health $24^{\text {th }}$ Report of the Royal Commission on Environmental Pollution (CM5827), London: The Stationery Office.

Royal Society and Royal Academy of Engineering (2004) Nanoscience and nanotechnologies: opportunities and uncertainties, Royal Society Policy Document $19 / 04$

Stern, P.C. \& Fineberg, H.V; eds. (1996) Understanding Risk: Informaing Decisions in a Democratic Society, Washington D.C.: National Academy Press.

Stirling, A. (2004) "Opening up or closing down? Analysis, participation and power in the social appraisal of technology" in Leach, M., Scoones, I. \& Wynne, B. (eds) (2004) Science, Citizenship and Globalisation London: ZED

Stilgoe, J. (in press) "The (co-)production of public uncertainty - UK scientific advice on mobile phone health risks", Public Understanding of Science

Stilgoe, J. (2005) "Controlling mobile phone risks in the UK: a fragile discourse of compliance", Science and Public Policy, 32, 1, 35-64.

The Copenhagen Charter: A Management Guide to Stakeholder Reporting (1999) Ernst \& Young, KPMG, PriceWaterhouseCoopers, House of Mandag Morgen.

Wilsdon, J. \& Willis, R. (2004) See-through Science: Why public engagement needs to move upstream, London:Demos

Woolgar, S. \& Pawluch, D. (1985) "Ontological Gerrymandering: The Anatomy of Social Problems Explanations", Social Problems Vol 32, No. 3, February p214-227.

Wynne, B. (1989a) Sheep farming after Chernobyl: A Case study in community scientific information Environment 31 p10-15, 33-39

Wynne, B. (1989b) "Frameworks of Rationality in Risk Management: Towards the Testing of Naïve Sociology" ch 3 in Brown J. (ed) Environmental Threats:

Perception, Analysis and Management London: Belhaven Press 
Wynne B (1992) Misunderstood Misunderstandings: social identities and public uptake of science, Public Understanding of Science, 1, 281-384

Wynne, B. (1996) "May the sheep safely graze? A reflexive view of the expert-lay knowledge divide" in Lash et al (eds) Risk, Environment and Modernity: Towards a New Ecology London: Sage 